\title{
The Comparison of the Plasma Levels of the Lead Element in Patients with Gastrointestinal Cancers and Healthy Individuals
}

\author{
Masoudreza Sohrabi ${ }^{1}$, Zahedin Kheiri ${ }^{2}$, Ali Gholami ${ }^{3}$, Mehran Haghighi ${ }^{1}$, \\ Fahimeh Safarnejad Temeshkel ${ }^{1}$, Mahmood Khoonsari ${ }^{1}$, Majid Reza Adelani ${ }^{1}$, \\ Amir Hossein Mirhosseini ${ }^{1}$, Melika Sohrabi ${ }^{4}$, Azam Rezaei Farimani ${ }^{5}$, Farhad \\ Zamani $^{1}$, Hossein Ajdarkosh ${ }^{1 *}$, Amir Hossein Faraji ${ }^{1 *}$
}

\begin{abstract}
Back ground and Aim: Heavy metals are considered as risk factors in the development of some types of cancers. In this context, the lead $(\mathrm{Pb})$ along with its biological impacts on the human body has raised significant concerns in public health. The aim of this study was to compare the plasma levels of the lead element in patients with gastrointestinal (GI) cancer and healthy subjects to examine whether this element has a role in the susceptibility of cancer. Methods: In a case-control study conducted between March 2016 to February 2017, the plasma levels of the lead were assessed. One-hundred patients with upper and lower GI cancers, as well as one-hundered healthy subjects who were age- and sex-matched participated in our study. A classic flame atomic absorption spectroscopy (FAAS) method was employed for the determination of the lead element in plasma levels of all subjects. Results: The mean age of patients was $53.8 \pm 10.6$ years old. The patient group consisted of 51 male and 49 female patients. The results showed that the concentrations of $\mathrm{Pb}$ were lower than the defined toxic levels. The comparison of the mean levels of $\mathrm{Pb}$ between the case and control groups revealed that there was no statistically significant difference even when the gender, age, and history of smoking were included in the statistical analysis. Our findings showed that the concentration of $\mathrm{Pb}$ is significantly associated with the type of cancer $(p<0.003)$ and the location of the tumor (whether upper or lower tract was affected) $(p<0.003)$. Conclusion: Lead may contributes to the pathology and progression of GI cancers but we can not conclude that it involved in the causation or susceptibility of healthy individuals to develop GI cancer.
\end{abstract}

Keywords: Lead- cancer- Gastrointestinal- trace elements

Asian Pac J Cancer Prev, 20 (9), 2639-2644

\section{Introduction}

In recent years, the incidence of cancer, especially gastrointestinal cancer (GI) is sharply increased in developing countries that it is thought the interplay between the environmental factors and genetic susceptibility plays a crucial role in the development of GI cancer (Koochak et al., 2016; Torre et al, 2015; Hemmasi et al., 2015; Anton-Culver et al., 2016; Rakhshani et al., 2014). Among environmental factors, heavy metals are involved in the causation and progression of many types of malignancies (Navarro Silvera and Rohan, 2007; Galanis et al., 2009). The lead element $(\mathrm{Pb})$ is one of the heavy metals which is broadly applied in numerous industrial products. The routes of exposure to $\mathrm{Pb}$ can occur via ingestion, inhalation, and dermal contact. Upon the entrance of $\mathrm{Pb}$ into the human body, it mediates some toxic reactions within the body and affects some organs such the central nervous system, reproductive, hematopoietic, and cardiovascular systems (Iarc et al., 2006; Fang et al., 2014). The source of environmental contamination varies as automobile exhaust, industrial wastewater, solid waste, cosmetic and paint products could contribute to the release of $\mathrm{Pb}$ into the environment. During the 1990s, the $\mathrm{Pb}$ toxicity in pediatric populations raised some concerns in the United States (US) and China (Li et al., 2014). They indicated that $\mathrm{Pb}$ toxicity could lead to intellectual and cognitive impairments and cause behavioral aberrations in children. It has been reported that another source of $\mathrm{Pb}$ contamination may stem from opium usage. In

${ }^{1}$ Gastrointestinal and Liver Diseases Research Center (GILDRC), Firoozgar Hospital, Iran University of Medical Sciences, ${ }^{4}$ Department of Analytic Chemistry, Faculty of Basic Sciences, Tehran Islamic Azad University, North Branch, Tehran, ${ }^{2}$ Department of Internal Medicine, Arak University of Medical Sciences, Arak, ${ }^{3}$ Noncommunicable Diseases Research Center, ${ }^{5}$ Department of Basic Medical Science, Neyshabur University of Medical Sciences, Neyshabur, Iran. *For Correspondence: ajdarkosh1345@yahoo.com, amirfaraji1350@gmail.com 
recent years, in some part of the Middle East where the consuming of opium is very common, the reports of $\mathrm{Pb}$ toxicity has tremendously increased. The lead element elevates the weight of opium without any change in its color or smell of the substance (Kamangar et al., 2014; Naghibzadeh Tahami et al., 2014). Hence, inhalation or ingestion of these products may cause $\mathrm{Pb}$ toxicity, and its side effects might influence the functionality of some organs in the human body. To date, there no definite cut off for $\mathrm{Pb}$ poisoning; thus, the intoxication may occur even at low concentrations of $\mathrm{Pb}$ (AAPC, 2005). According to reports of the American Academy of Pediatrics, between 2007 and 2010, approximately $2.6 \%$ of pre-school children in the US had plasma levels of $\mathrm{Pb}$ higher than $0.05 \mu \mathrm{g} /$ $\mathrm{ml}$ which caused neurobehavioral problems in children. However, there was no linear correlation between the concentrations of $\mathrm{Pb}$ and the severity of side effects in children exposed to $\mathrm{Pb}$ (AAPC, 2016). There is no cure for individuals intoxicated with $\mathrm{Pb}$ (Garcia-Leston et al., 2010; Silbergeld et al. , 2000). Although human studies have not definitely confirmed the link between cancer and $\mathrm{Pb}$ toxicity, especially GI cancer, but a number of animal studies have suggested that exposure to inorganic $\mathrm{Pb}$ increases the risk of kidney, lung, brain, and hematopoietic cancers(Saghiri et al., 2016; Chan et al., 2015). Despite the increasing knowledge about the genotoxicity of $\mathrm{Pb}$, the mechanism underlying this phenomenon is still opaque. It has been proposed that $\mathrm{Pb}$ may induce inflammation, oxidative stress, and inhibit DNA repair, as well as causing genetic mutations in human beings when exposed to $\mathrm{Pb}$ for a long-term period. Previous studies demonstrated that $\mathrm{Pb}$ is involved in some signaling pathways which contribute to inflammation and neutrophil activity and consequently can cause cellular damages (Kim et al., 2015; Lin et al., 2015; Garcia-Leston et al., 2010). Therefore, the abnormal concentrations of $\mathrm{Pb}$ may have a marked impact on cell biology and could be considered a carcinogen compound. In this case-control study, we evaluated the concentrations of $\mathrm{Pb}$ in plasma samples of patients with gastrointestinal cancers in comparison with healthy subjects.

\section{Materials and Methods}

\section{Study design and sample collection}

This case-control study was conducted in Firoozgar Hospital affiliated to the Iran University of Medical Sciences. Data were collected from March 2016 to February 2017. One-hundred patients diagnosed with gastrointestinal cancers, by histopathological examinations, were enrolled in this study. The same number of healthy individuals who were age- and sex-matched were also included in our study as a control group. The exclusion criteria for the selection of patients with GI cancers were as follows; disagreement of patients, history of malignancies other than gastrointestinal cancers, history of metabolic or nutritional disorders, the regular use of a particular medication/hormones/ chelators, receiving chemotherapy or radiations. The process of the selection of healthy individuals was based on those subjects referring to the hospital for the annual check-up, and they were devoid of any GI problems. The same exclusion criteria were met for the selection of the control group except for "receiving chemotherapy and radiation" that was not applicable and meaningful for healthy individuals.

Demographic and clinical characteristics of participants A questionnaire including demographic (age, sex, and history of smoking) and clinical (the type and location of GI cancers) was given to each patient or healthy individual.

\section{Diagnosis and classification of GI cancers}

GI cancers were divided into four categories including gastric, esophageal, colon, and rectosigmoid cancers. Also, the site of GI tumors was assigned into two classifications according to their anatomical location namely, lower and upper gastrointestinal cancers. Lower gastrointestinal malignancies included colon and rectosigmoid cancers and upper gastrointestinal cancers consisted of the esophagus and gastric cancers.

\section{Measurement of plasma $\mathrm{Pb}$ \\ Sample Preparation}

Acid digestion was employed for the preparation of the blood samples. Venous blood samples were obtained from all participants and immediately poured in heparin-containing tubes. Samples were agitated by the hand and centrifuged at 2,000 rpm for $10 \mathrm{~min}$. The plasma was separated and stored at $-70^{\circ} \mathrm{c}$ until analyzed. At the laboratory, $3 \mathrm{ml}$ of samples were digested with $65 \% \mathrm{HNO}_{3}-30 \% \mathrm{H}_{2} \mathrm{O}_{2}$ mixture $(10: 1 \mathrm{v} / \mathrm{v})$ and heated until dense white fumes appeared. Samples were cooled down to room temperature, filtered, and then diluted to a proper volume with double distilled water. The final solution was injected to the FAAS in order to determine the concentration of $\mathrm{Pb}$ in plasma specimens.

\section{Instrument}

The flame atomic absorption spectroscopy (FAAS) method, using the Varian model spectra AA-240 (Mulgrara, Victoria, Australia) was used to assess the levels of $\mathrm{Pb}$ in plasma samples. An Alpha silver heater and Mettler College 150 balances were used. The parameters for the instrument were set based on the manufacturer's recommendations.

\section{Reagents}

All reagents and solvents were procured from Merck Company (Germany). Nitric acid (65\%) and double distilled water were used to wash the glassware. Nitric acid $(65 \%)$ and hydrogen peroxide (30\%) were also employed for the digestion procedures. In the next step, standard solutions for the measurement of $\mathrm{Pb}$ were prepared in a range of $0.05-3 \mu \mathrm{g} / \mathrm{ml}$. The calibration curve was obtained using the analysis of the standard solutions at a wavelength of $217 \mathrm{~nm}$, HC Lamp Current (5mA) and Slit width (1 nm).

\section{Statistical analysis}

The analysis of the data obtained in this study was performed by the SPSS software version 22 (SPSS, Chicago, IL). The Shapiro-Wilk test was used to determine 
whether the data were normally distributed. The Wilcoxon and Kruskal-Wallis tests were used for the comparison of the levels of $\mathrm{Pb}$ between the case and control groups where appropriate. The confidence interval was set at $95 \%$, and the difference between the two groups was considered statistically significant if the $p$-value was less than 0.05 . The age of participants was categorized into three groups as follows; $<50$ years, $50-59$ years, and $\geq 60$ years. Smoking history was expressed as the Yes/No answer.

\section{Ethical considerations}

This study was approved by the Ethics Committee of the Iran University of Medical Sciences, Firoozgar Hospital. Before the commencement of the study, all subjects were given informed consents. The experimental protocol was designed and carried out according to the principles of the Helsinki Declaration.

\section{Results}

Among one-hundred patients with GI cancers, 51 patients were male possessing the mean age of $53.8 \pm 10.6$ years old. More than two-thirds of the patients suffered from gastric ( 37 patients) and colon cancers (34 patients). The same number of healthy individuals was employed in the control group which was age- and sex matched with the case group (Table 1).

In this study, half of GI cancers were related to the lower gastrointestinal tracts. The plasma concentrations of $\mathrm{Pb}$ in patients with cancer were presented in Table 1.
As shown in Table 1, although the concentration of plasma $\mathrm{Pb}$ in the case group was not significantly correlated with gender $(\mathrm{p}=0.49)$, age $(\mathrm{p}=0.38)$, and history of smoking $(p=0.55)$, the levels of plasma $\mathrm{Pb}$ was statistically associated with the types $(\mathrm{p}=0.003)$ and the tumor site of GI cancers $(p=0.003)$.

Tables 1 and 2 also showed that similar findings were obtained from the comparison of plasma levels of $\mathrm{Pb}$ with gender $(p=0.71)$, age $(p=$ ?), and history of smoking $(p=0.56)$ in healthy subjects. Finally, as indicated in Table 3, no significant difference was observed in the concentration of $\mathrm{Pb}$ between the case and control group when gender, age, and history of smoking were considered (all p-values $>0.05$ ).

\section{Discussion}

In the present study, we attempted to determine the association between the plasma concentrations of $\mathrm{Pb}$ and the susceptibility of GI cancers. There was no statistically significant difference in plasma levels of $\mathrm{Pb}$ between the healthy subjects and patients with GI cancers. However, there was a significant correlation between the concentration of $\mathrm{Pb}$ and the type and tumor site of GI cancers.

The National Institute for Occupational Safety and Health (NIOSH) indicated that the normal plasma levels of $\mathrm{Pb}$ were defined as $0.05 \mu \mathrm{g} / \mathrm{ml}$ for adults (Alarcon et al., 2015). Besides, $\mathrm{Pb}$ intoxication-induced the central nervous system dysfunction has been reported when the

Table 1. Descriptive Statistics of Blood Pb Concentration $(\mu \mathrm{g} / \mathrm{ml})$ in Patients and Healthy Controls Based on Different Characteristics of Study Population

\begin{tabular}{|c|c|c|c|c|c|c|c|c|}
\hline Variables & & & $\mathrm{N}$ & Median & Mean & SD & Minimum & Maximum \\
\hline \multirow[t]{4}{*}{ Gender } & Male & Case & 51 & 0.022 & 0.14 & 0.27 & 0.04 & 1.11 \\
\hline & & Control & 51 & 0.039 & 0.04 & 0.04 & 0 & 0.161 \\
\hline & Female & Case & 49 & 0.028 & 0.15 & 0.35 & 0 & 2.08 \\
\hline & & Control & 49 & 0.039 & 0.04 & 0.04 & 0 & 0.161 \\
\hline \multirow[t]{6}{*}{ Age categories } & $<50 \mathrm{y}$ & Case & 36 & 0.03 & 0.2 & 0.43 & 0 & 2.08 \\
\hline & & Control & 36 & 0.039 & 0.04 & 0.04 & 0 & 0.161 \\
\hline & $50-60 y$ & Case & 34 & 0.02 & 0.13 & 0.21 & 0 & 0.92 \\
\hline & & Control & 34 & 0.044 & 0.04 & 0.03 & 0 & 0.106 \\
\hline & $>60 y$ & Case & 30 & 0.02 & 0.08 & 0.21 & 0 & 1.11 \\
\hline & & Control & 30 & 0.011 & 0.03 & 0.04 & 0 & 0.161 \\
\hline \multirow[t]{4}{*}{ History of Smoking } & No & Case & 36 & 0.022 & 0.14 & 0.39 & 0 & 2.08 \\
\hline & & Control & 45 & 0.039 & 0.04 & 0.03 & 0 & 0.106 \\
\hline & Yes & Case & 64 & 0.028 & 0.14 & 0.26 & 0 & 1.11 \\
\hline & & Control & 55 & 0.033 & 0.04 & 0.04 & 0 & 0.161 \\
\hline \multirow[t]{4}{*}{ Type of Cancer } & Esophagus & Case & 13 & 0.033 & 0.19 & 0.32 & 0 & 1.11 \\
\hline & Gastric & Case & 37 & 0 & 0.13 & 0.39 & 0 & 2.08 \\
\hline & Colon & Case & 34 & 0.028 & 0.14 & 0.27 & 0 & 0.92 \\
\hline & Rectal & Case & 16 & 0.061 & 0.14 & 0.15 & 0.017 & 0.46 \\
\hline \multirow[t]{2}{*}{ Location of cancer } & Upper & Case & 50 & 0.011 & 0.14 & 0.37 & 0 & 2.08 \\
\hline & Lower & Case & 50 & 0.033 & 0.14 & 0.24 & 0 & 0.92 \\
\hline Total & & Case & 100 & 0.14 & 0.03 & 0.31 & 0 & 2.08 \\
\hline Total & & Control & 100 & 0.039 & 0.04 & 0.04 & 0 & 0.161 \\
\hline
\end{tabular}


Table 2. Comparison of $\mathrm{Pb}$ Concentration $(\mu \mathrm{g} / \mathrm{ml})$ in Blood of Cases and Healthy Controls with Use of Wilcoxon Rank-Sum and Kruskal-Wallis Rank Tests According to Different Characteristics of Study Population

\begin{tabular}{|c|c|c|c|c|c|}
\hline & Variable & & Median & $\mathrm{Z}$ or $\mathrm{X}^{2}$ & $P$-value \\
\hline \multirow[t]{2}{*}{ Case group } & Gender & Male & 0.022 & 0.695 & 0.49 \\
\hline & & Female & 0.028 & & \\
\hline \multirow[t]{2}{*}{ Control group } & & Male & 0.039 & 0.362 & 0.71 \\
\hline & & Female & 0.039 & & \\
\hline \multirow[t]{3}{*}{ Case group } & Age categories & $<50$ & 0.03 & 1.95 & 0.38 \\
\hline & & $50-60$ & 0.02 & & \\
\hline & & $>60$ & 0.02 & & \\
\hline \multirow[t]{3}{*}{ Control group } & Age categories & $<50$ & 0.039 & 5.92 & 0.051 \\
\hline & & $50-60$ & 0.044 & & \\
\hline & & $>60$ & 0.011 & & \\
\hline \multirow[t]{2}{*}{ Case group } & History of Smoking & No & 0.022 & -0.592 & 0.55 \\
\hline & & Yes & 0.028 & & \\
\hline \multirow[t]{2}{*}{ Control group } & History of Smoking & No & 0.039 & 0.587 & 0.56 \\
\hline & & Yes & 0.033 & & \\
\hline \multirow[t]{4}{*}{ Case group } & Type of Cancer & Gastric & 0.000 & 13.68 & 0.003 \\
\hline & & Esophagus & 0.033 & & \\
\hline & & Colon & 0.028 & & \\
\hline & & Rectal & 0.061 & & \\
\hline \multirow[t]{2}{*}{ Case group } & Location of cancer & Upper & 0.011 & 2.93 & 0.003 \\
\hline & & Lower & 0.033 & & \\
\hline
\end{tabular}

Table 3. Comparison of $\mathrm{Pb}$ Concentration $(\mu \mathrm{g} / \mathrm{ml})$ in Blood of Cases and Healthy Controls with Use of Wilcoxon Matched-Pairs Signed- Ranks Test According to Different Characteristics of Study Population

\begin{tabular}{llcccc}
\hline variable & & \multicolumn{2}{c}{ Median } & Wilcoxon & P value \\
& & Case & Control & Z test & \\
\hline Gender & Male & 0.022 & 0.039 & -0.966 & 0.33 \\
& Female & 0.028 & 0.039 & -0.443 & 0.66 \\
Age categories & $<50$ & 0.03 & 0.039 & -1.078 & 0.28 \\
& $50-60$ & 0.02 & 0.041 & -0.385 & 0.7 \\
& $>60$ & 0.02 & 0.011 & -0.382 & 0.7 \\
\hline
\end{tabular}

plasma levels of $\mathrm{Pb}$ is in a range of $0.82-1.44 \mu \mathrm{g} / \mathrm{ml}$. Additionally, the toxic levels of $\mathrm{Pb}$ for the gastrointestinal tract dysfunction has been defined in a range of 0.41-0.82 $\mu \mathrm{g} / \mathrm{ml}$ (Chan et al., 2015). In this study, the concentration of $\mathrm{Pb}$ did not reach the above ranges mentioned earlier. But, it seems that cancer-prone tissues such as the GI tract have high sensitivity to $\mathrm{Pb}$-induced damage even at lower concentrations. In this context, animal studies demonstrated that exposure to inorganic $\mathrm{Pb}$ causes kidney, lung, and brain cancers (Rousseau et al., 2007; Chan et al., 2015; Wynant et al., 2013). Furthermore, the tissue concentration of $\mathrm{Pb}$ could be regarded as an issue that needs to be more taken into account. Although it is not clear whether the low levels of $\mathrm{Pb}$ could contribute to the development of GI cancers, it is likely that $\mathrm{Pb}$ might trigger, along with other carcinogen agents, environmental or genetic factors which are thought to be involved in the etiology of GI cancers (Sohrabi et al., 2017).

International Agency for Research on Cancer (IARC) has shown that $\mathrm{Pb}$ might be carcinogenic for the human body (Kim et al., 2015). There are few studies on GI cancers and plasma levels of $\mathrm{Pb}$. In this line, some studies performed on labors who were exposed to $\mathrm{Pb}$ suggested that $\mathrm{Pb}$ may be involved in the development of specific types of malignancies such as lung and gastric cancers (Wingren and Axelson, 1993; Gerhardssonet et al., 1995; Gerhardsson et al., 1986; Pukkala et al., 2009). In the year of 2008, Khorasani et al., in a case-control study, measured the plasma levels of $\mathrm{Pb}$ in patients with gastric cancer and healthy subjects. They found that the plasma levels of $\mathrm{Pb}$ were higher in patients with gastric cancer compared with the control group.

Furthermore, Rousseau and colleagues showed that men workers who were exposed to had a higher risk of developing gastric cancer compared with the general population; however, the risk of other types of cancer was not significantly higher in male labors when compared with the other people. In contrast, Lam et al. indicated that there was no significant association between the exposure of male workers to $\mathrm{Pb}$ and the risk of gastric cancer. In the present study, we indicated that the concentrations of $\mathrm{Pb}$ in patients with lower GI cancers were higher than patients with upper GI cancers. Also, our previous study showed that concentrations of $\mathrm{Pb}$ in patients with colon cancer were higher in cancerous tissue as compared with non-cancerous tissues (Sohrabi et al., 2017). Generally, the exposure to $\mathrm{Pb}$ occurs in the upper GI tract since the main route of $\mathrm{Pb}$ contamination is mediated by ingestion and inhalation. Hence, it would be plausible that the rate of upper GI cancers is higher than the lower GI cancers. It is alleged that the blood circulation can transfer the 
lead element to other organs within the human body and therefore, the systemic circulation plays a central role in the susceptibility of lower GI cancers in individuals exposed to $\mathrm{Pb}$. It seems that $\mathrm{Pb}$ is idiopathically accumulated in the lower GI tract and increases the risk of GI cancers in individuals prone to develop GI cancer. To date, though there is no consensus on the carcinogenicity of $\mathrm{Pb}$ in the literature, the detrimental effects of the lead element is undeniable on the biological reactions occurred within the human body such as the inhibition of DNA repair.

In 2006, Dobrakowski and collogues exhibited that chronic and sub-chronic exposure to $\mathrm{Pb}$ may increase inflammation activity and induce pro-inflammatory cytokines and non-enzymatic antioxidants, such as bilirubin. Regardless of the free radical scavenging role of bilirubin, higher levels of bilirubin are capable of inhibiting the biosynthesis of the heme molecule (Dobrakowski et al., 2014; Annabi Berrahal et al., 2007; Aziz et al., 2018). Pb can also influence the cellular inflammatory response and enhance the angiogenesis process. Moreover, this element has indirect genotoxic potentials when administered in combination with other DNA-damaging agents, suggesting a possible co-carcinogenic effect (Rousseau et al., 2007; Lin et al., 2015). Therefore, it would be expected that $\mathrm{Pb}$ can trigger the cellular damages in the lower tract of GI cancers after the absorption via the different cell signaling pathways.

In conclusion, the concentration of $\mathrm{Pb}$ did not exceed the toxic levels in plasma levels of either patients or healthy individuals. However, we could not rule out the side effects of $\mathrm{Pb}$ on DNA and inflammation. In the present study, it was shown that the concentration of $\mathrm{Pb}$ was linked with the type and tumor site (upper and lower GI cancers). It appears that the rout of exposure to $\mathrm{Pb}$ does not play a significant role in the development of GI cancers.

\section{References}

Alarcon WA (2015). Summary of notifiable noninfectious conditions and disease outbreaks: Elevated blood lead levels among employed adults - United States, 1994-2012. MMWR Morb Mortal Wkly Rep, 62, 52-75.

Annabi Berrahal A, Nehdi A, Hajjaji N, Gharbi N, El-Fazaa S (2007). Antioxidant enzymes activities and bilirubin level in adult rat treated with lead. $C R$ Biol, 330, 581-8.

Anton-Culver H, Chang J, Bray F, et al (2016). Cancer burden in four countries of the Middle East Cancer Consortium (Cyprus; Jordan; Israel; Izmir (Turkey) with comparison to the United States surveillance; epidemiology and end results program. Cancer Epidemiol, 44, 195-202.

Aziz MH, Sideras K, Aziz NA, et al (2018). The systemicimmune-inflammation index independently predicts survival and recurrence in resectable pancreatic cancer and its prognostic value depends on bilirubin levels: A retrospective multicenter cohort study. Ann Surg, 2018, 12.

Chan CP, Tsai YT, Chen YL, et al (2015). Pb2+ induces gastrin gene expression by extracellular signal-regulated kinases $1 / 2$ and transcription factor activator protein 1 in human gastric carcinoma cells. Environ Toxicol, 30, 129-36.

Dobrakowski MA, Kasperczyk NPE, Birkner E Hudziec, Chwalinska E, Kasperczyk S (2016). Association between subchronic and chronic lead exposure and levels of antioxidants and chemokines. Int Arch Occup Environ Health, 89, 1077-85.

Dobrakowski M, Kasperczyk A, Pawlas N, et al (2014). The effect of occupational exposure to lead on the non-enzymatic antioxidant system. Med Pr, 65, 443-51.

Fang JY, Wang PW, Huang CH, Hung YY, Pan TL (2014). Evaluation of the hepatotoxic risk caused by lead acetate via skin exposure using a proteomic approach. Proteomics, 14, 2588-99.

Inorganic and organic lead compounds (2006). IARC Monogr. Eval Carcinog Risks Hum, 87, 1-471.

Galanis A, Karapetsas A, Sandaltzopoulos R (2009). Metal-induced carcinogenesis, oxidative stress and hypoxia signalling. Mutat Res, 674, 31-5.

Galanis A, Karapetsas A, Sandaltzopoulos R (2010). Genotoxic effects of lead: an updated review. Environ Int, 36, 623-36.

Gerhardsson L, Hagmar L, Rylander L, Skerfving S (1995). Mortality and cancer incidence among secondary lead smelter workers. Occup Environ Med, 52, 667-72.

Gerhardsson L, Lundstrom NG, Nordberg G, Wall S (1986). Mortality and lead exposure: a retrospective cohort study of Swedish smelter workers. Br J Ind Med, 43, 707-12.

Hemmasi G, Sohrabi M, Zamani F, et al (2015). Prevalence of colorectal adenoma in an average-risk population aged 40-50 versus 50-60 years. Eur J Cancer Prev, 24, 386-90.

Kamangar F, Shakeri R, Malekzadeh R, Islami F (2014). Opium use: an emerging risk factor for cancer?. Lancet Oncol, 15, e69-77.

Khorasani G, Shokrzade M, Salehifar E, et al (2008). The comparison of lead and zinc plasma levels in gastric cancer patients with healthy volunteers. Res Jo Biol Sci, 3, 631-4.

Kim HC, Jang TW, Chae HJ, et al (2015). Evaluation and management of lead exposure. Ann Occup Environ Med, 27, 30 .

Koochak A, Rakhshani N, Karbalaie Niya M, et al (2016). Mutation analysis of $K R A S$ and $B R A F$ genes in metastatic colorectal cancer: a first large scale study from Iran. Asian Pac J Cancer Prev, 17, 603-8.

Lam TV, Agovino P, Niu X, Roche L (2007). Linkage study of cancer risk among lead-exposed workers in New Jersey. Sci Total Environ, 372, 455-62.

Li MM, Cao J, Xu J, et al (2014). The national trend of blood lead levels among Chinese children aged 0-18 years old, 1990-2012. Environ Int, 71, 109-17.

Lin YC, Wei PL, Tsai YT, Wong JH, Chang CM (2015). $\mathrm{Pb}(2)(+)$ induced IL-8 gene expression by extracellular signal-regulated kinases and the transcription factor, activator protein 1, in human gastric carcinoma cells. Environ Toxicol, 30, 315-22.

Lead exposure in children: prevention, detection, and management (2005). Pediatrics, 116, 1036-46.

Naghibzadeh Tahami A, Khanjani N, Yazdi Feyzabadi V, Varzandeh M, Haghdoost AA (2014). Opium as a risk factor for upper gastrointestinal cancers: a population-based case-control study in Iran. Arch Iran Med, 17, 2-6.

Navarro Silvera SA, Rohan TE (2007). Trace elements and cancer risk: a review of the epidemiologic evidence. Cancer Causes Control, 18, 7-27.

Pukkala E, Martinsen JI, Lynge E, et al (2009). Occupation and cancer - follow-up of 15 million people in five Nordic countries. Acta Oncol, 48, 646-790.

Rakhshani N, Kalantari E, Bakhti H, Sohrabi MR, Mehrazma M (2014). Evaluation of HER-2/neu overexpression in gastric carcinoma using a tissue microarray. Asian Pac J Cancer Prev, 15, 7597-7602.

Rousseau MC, Parent ME, Nadon L, Latreille B, Siemiatycki J (2007). Occupational exposure to lead compounds and risk 
of cancer among men: a population-based case-control study. Am J Epidemiol, 166, 1005-14.

Saghiri MA, Orangi J, Asatourian A, Sorenson CM, Sheibani N (2016). Functional role of inorganic trace elements in angiogenesis part III: (Ti, Li, Ce, $\mathrm{As}, \mathrm{Hg}, \mathrm{Va}, \mathrm{Nb}$ and $\mathrm{Pb}$ ). Crit Rev Oncol Hematol, 98, 290-301.

Silbergeld EK, Waalkes M, Rice JM (2000). Lead as a carcinogen: experimental evidence and mechanisms of action. Am J Ind Med, 38, 316-23.

Sohrabi M, Gholami A, Azar MH, et al (2018). Trace element and heavy metal levels in colorectal cancer: Comparison between cancerous and non-cancerous tissues. Biol Trace Elem Res, 183, 1-8

Torre LA, Bray F, Siegel RL, et al (2015). Global cancer statistics, 2012. CA Cancer J Clin, 65, 87-108.

Wingren G, Axelson O (1993). Epidemiologic studies of occupational cancer as related to complex mixtures of trace elements in the art glass industry. Scand J Work Environ Health, 19, 95-100.

Wynant W, Siemiatycki J, Parent ME, Rousseau MC (2013). Occupational exposure to lead and lung cancer: results from two case-control studies in Montreal, Canada. Occup Environ Med, 70, 164-70.

\section{बळब}

This work is licensed under a Creative Commons AttributionNon Commercial 4.0 International License. 